\title{
SSD EFFICIENCY AT MULTIPLE DATA FREQUENCIES: APPLICATION ON THE OECD COUNTRIES
}

\section{Umut Ugurlu, Oktay Tas, Celal Barkan Guran, Aysun Guran*}

\begin{abstract}
The second order stochastic dominance (SSD) has become exceedingly popular in recent years, due to its ability to determine the dominance of one asset over another for all risk-averse investors without a strict requirement in asset distribution. In this study, 33 OECD country indexes and their enriched set of assets, which consists of some combinations of these indexes, are investigated and compared between 2007 and 2015 by utilizing pairwise SSD comparisons, with different data frequencies, such as daily, weekly, monthly and quarterly. This paper contributes to the literature in three points: Firstly, a serious portion of the best performing OECD countries has the lowest GDP (PPP) per capita level. Secondly, the SSD efficient set depends on data frequency. Thirdly, when the data frequency is lowered, the difference between two SSD pairwise efficiency tests decreases.
\end{abstract}

Keywords: second order stochastic dominance, SSD pairwise efficiency, pairwise comparisons, data frequency, OECD indexes

JEL Classification: G11, G14, C61

\section{Introduction}

Most of the analyses of financial instruments on both academic and industrial environment require historical data which can be accessed in different data frequencies; such as daily, weekly, monthly and quarterly. At a constant investment horizon, various types of investor's interest in different data frequencies and these differences bring variations in final results.

Portfolio selection plays an important role among these analyses in today's financial world. Although there are many ways to select among different portfolios, one of which is human intuition, best results are usually achieved by utilizing modern scientific optimization methods. As a pioneer optimization tool, Markowitz (1952) has set the standard for portfolio optimization by inventing the Mean-Variance (MV) model, which is still used. Following his footsteps, many improvements and expansions in portfolio optimization have been proposed in the last 60 years.

Umut Ugurlu, Management Engineering Department, Istanbul Technical University, Turkey (ugurluum@itu.edu.tr);

Oktay Tas, Management Engineering Department, Istanbul Technical University, Turkey (oktay.tas@itu.edu.tr);

Celal Barkan Guran, Management Engineering Department, Istanbul Technical University, Turkey (guranc@itu.edu.tr);

Aysun Guran, Computer Engineering Department, Dogus University, Turkey (adogrusoz@dogus.itu. edu.tr). 
Most notable portfolio optimization methods, which were introduced following Markowitz, are Jensen Alpha (1968), Sharpe Ratio (1966), and Treynor Measure (1966), and they have been routinely used in the financial world. These portfolio performance measures require at least two portfolios to function. Additionally, they only use the first and second moments, mean and variance, respectively, to provide solutions. In other words, they do not count the third and fourth moments, skewness and kurtosis, respectively, into account.

In an effort to overcome the shortcomings ${ }^{1}$ of the previous methods, the second order stochastic dominance (SSD) was invented by Hanoch and Levy (1969). In essence, their method makes it possible to evaluate just a single portfolio by SSD efficiency with the help of pairwise comparisons of all belonging assets. Unlike methods that rely on MV, SSD does not require normal distribution. A noteworthy exception in applying the SSD method is that it must only be used for risk-averse investors. This means, it is only available for concave utility functions; but this limitation is not an important issue since most of the financial operations are conducted for risk-averse investors.

For the empirical study, the indexes of 33 OECD countries are selected since they all have stock exchanges and relatively deep economies. The purpose of this analysis can be summarized as follows: The first part analyses the indexes of all 33 countries and compares them with each other in terms of SSD pairwise comparison and performs an SSD pairwise efficiency test. The second part discusses the effects of data frequency changes by contrasting daily frequency with weekly, monthly and quarterly frequencies.

Section 2 gives a literature review of the portfolio optimization referring stochastic dominance. Section 3 explains the theoretical background of stochastic dominance. Section 4 is the empirical part. Section 5 states the results of the application. Section 6 consists of the conclusion and future research.

\section{Literature Review}

The stochastic dominance method has been utilised in many papers, for portfolio and also for pairwise efficiency. Related papers are discussed below.

Hodder et al. (2015) mention that all risk-averse investors tend to choose the SSD and would prefer a dominating portfolio. However, it is still a challenging problem choosing among the SSD efficient portfolios. This paper compares SSD-based techniques of Kuosmanen (2004) and Kopa and Post (2015) with other SSD-related strategies and event to the conventional portfolio choice methods. Overall, SSD-related techniques outperform portfolios chosen according to their Sharpe ratio, information ratio, or using equal weights. Portfolios based on minimum variance also match the benchmark's mean return perform almost equal to the SSD-related choices. This recent paper gives an opinion about the importance and the performance of SSD-related methods by taking two especially important SSD-related methods into account.

According to Best et al. (2000) value portfolios second order stochastically dominate growth portfolios. There are 10 portfolios, which are set from the NYSE, AMEX and

1 The shortcomings of MV are deeply discussed in Kraus and Litzenberger (1976), Post et al. (2008). 
NASDAQ nonfinancial firms. Portfolios are ranked according to book to market equity ratios. Value portfolios, which have higher book to market ratios, dominate low book to market portfolios.

Fong (2009) concludes that in Chinese stock marketA-shares second order stochastically dominate B-shares. It means that all risk averse investors will prefer A-shares to B-shares. However, SSD relationship is not because of the risk characteristics of the Chinese market, but due to the inefficiency of Chinese stock market in the observation period.

Güran et al. (2013) observe the efficiency of Turkish, BIST-30 Index portfolio by SSD. Data is used from 3 December 2010 to 5 July 2013 on weekly basis. All 30 stocks are second order stochastically pairwise compared. Only 12 of 30 stocks are not second orderly dominated and can be used in an efficient portfolio of BIST-30. Total weight of these 12 stocks is $34.64 \%$. In accordance with these results, BIST-30 is not an SSD efficient index.

Branda and Kopa (2012) uses 25 world financial indexes for two periods, which are represented as before crisis, from 11 September 2006 to 15 September 2008, during crisis, and from 16 September 2008 to 20 September 2010. According to SSD portfolio efficiency test, only the index with the highest mean is efficient in both periods. It is Ibovespa before the crisis and Jakarta Composite Index during the crisis. It means that all risk-averse investors prefer some combination of other indexes to the index. There are also SSD pairwise efficiency tests and 10 of the indexes are pairwise efficient before the crisis and 5 of them are efficient during the crisis. Only BSE Sensex and Jakarta Composite Index are SSD pairwise efficient in both periods. Our paper tries to extend this work by using more indexes in a different time period and also contributes to the literature by analysing the effects of various data frequencies.

Kopa and Tichy (2014) analyse the performance of mean-risk efficient portfolios by various methods of portfolio comparison. In this sense, SSD efficiency of portfolios on the efficient frontier is analysed according to different risk measures such as standard deviations and concordance matrices. This work uses selected Asia-Pacific stock markets by taking local, U.S. dollar and euro as reference currencies and investigating them before and during the subprime crisis separately. Moreover, the paper also proposes two different models with and without short-selling. The notion of SSD was applied and the SSD efficiency test of Kuosmanen (2004) was executed to 11 Asia-Pacific stock market indexes. According to the results, almost all minimum-variance portfolios were SSD inefficient. On the other hand, portfolios with the highest mean were always SSD efficient. If the conditions on minimal mean return were applied, then minimal required return increases and SSD inefficiency measures decrease among the mean-risk efficient portfolios. Another contribution is that allowance of short-selling sharply decreases the number of SSD efficient portfolios and only $2-3 \%$ of mean-risk efficient portfolios were classified as SSD efficient. Lastly, for the Pearson concordance measure, before the crisis there were more SSD efficient portfolios on the efficient frontier than during the crisis period. However, for other two concordance measures, Spearman and Kendall, the same finding could not be found. 
Tas et al. (2015) examine the impact of using different weighting methods on the classification of SSD efficient portfolios. Different weighting methods such as equal, simple and logarithmic were applied on the Dow Jones Industrial Average (DJIA) and Borsa Istanbul (BIST) indexes. Results illustrate that there are differences in SSD efficient sets according to various weighting methods. Working with one emerging and one developed market also gave the chance of investigating the market efficiency of both markets New York Stock Exchange (NYSE) and BIST. The SSD efficient set of Turkish market hardly outperformed the market index, BIST-30. On the contrary, the SSD efficient sets out of DJIA easily outperform the market index. It could be a sign of that NYSE is more efficient than BIST.

Güran and Tas (2015) combine SSD with Mean-Variance theory. Firstly, they eliminate the inefficient stocks by SSD, and then they apply Mean-Variance optimization to the SSD efficient subset. It takes Turkish, BIST-30 market index as an empirical example. After the application of this method, the Sharpe's ratio maximizing portfolio is selected and compared with the BIST-30 index. Although there is not an important difference between the returns and standard deviations, this paper expands the perspective of Mean-Variance optimization by applying SSD pairwise efficiency as a preliminary test.

Although in this paper only an improved version of pairwise SSD efficiency test will be applied, a lot of portfolio efficiency tests were developed (Post, 2003; Kuosmanen, 2004; Kopa and Chovanec, 2008; Dupacova and Kopa, 2012; Lizyayev, 2012; Post and Kopa, 2013; Grechuk, 2014; Linton et al., 2014; Kopa and Post, 2015). Due to computational intractability of these tests, the paper is enriched by an enhanced type of pairwise SSD efficiency test.

Stochastic dominance efficiency tests of Post (2003) and Kuosmanen (2004) are milestones in portfolio efficiency tests and as mentioned by Post (2003) they provided a "stimulus to the further proliferation" in stochastic dominance efficiency tests. Post (2003) proposed empirical tests for stochastic dominance efficiency of a given portfolio with respect to all possible portfolios constructed from a set of assets. The tests were computed by linear programming and bootstrapping techniques and asymptotic distribution theory were utilised. According to the results, Fama and French market portfolio is significantly inefficient compared to benchmark portfolios, constructed due to market capitalization and book-to-market equity ratio. Kuosmanen (2004) develops another linear programming test and it is based on comparisons of cumulated returns. This test finds a dominating portfolio, however, it does not need to be SSD efficient. It is a relatively computationally demanding test.

Kopa and Chovanec (2008) detect a dominating portfolio which is SSD efficient, contrary to the previous works of Post (2003) and Kuosmanen (2004). It also suggests a new linear programming portfolio efficiency test for portfolios with scenario approach for outcome distributions and also a new SSD portfolio inefficiency measure. The test depends on the relationship of CVaR and dual SSD. The computed efficiency measure shows a distance between the tested portfolio and its least risky dominating portfolio. This measure is also found consistent with the SSD relation and due to the convexity of this measure, it is used to describe the set of SSD efficient portfolios. 
Lizyayev (2012) proposes the first systematic review in a methodological framework for this emerging topic, stochastic dominance efficiency analysis. Mainly efficiency testing was classified under three categories: "majorization", "revealed preference" and "distribution-based approaches". Although all of them try to contribute in the literature, there is only a little interaction and cross-referencing among them. Furthermore, purposes, information content, results and computational difficulty differ from method to method. This paper examines the main developments in this literature and discusses the advantages and disadvantages of all of them. It also states the misleading arguments and proposes some corrections and improvements.

In a recent paper Kopa and Post (2015) develop a linear programming test to analyse the efficiency of a given portfolio with respect to all possible portfolios formed from a set of main assets. Authors propose a dual model. If the evaluated portfolio is efficient, the primary model identifies a sub-gradient vector of utility function, which rationalizes the evaluated portfolio. If it is inefficient, then the second model finds out an efficient portfolio that dominates the evaluated portfolio. The test is capable of giving the general necessary and sufficient condition, and it can deal with general linear portfolio restrictions, inefficiency degree measures and scenarios with unequal probabilities. The proposed dual model also reduces the computational time. In the application part, U.S. broad stock market index found as significantly inefficient and it is asserted that no risk-averse investor would prefer the market index to some more concentrated investment portfolios. These findings are similar to the findings of Kopa and Post (2009), Post and Kopa (2013) and Post et al. (2015). All of these papers show the inefficiency of the stock market portfolio with respect to different types of stochastic dominance.

The underlying desire to write this paper was, although a fixed data frequency has been used in many other papers, it is not usually stated, or readily obvious, how or why a particular data frequency is selected: Best et al. (2000), Kopa and Tichy (2012), Fong (2009), Al-Khazali et al. (2014), Tas et al. (2015) use daily; Branda and Kopa (2012), Güran et al. (2013), Güran and Tas (2015) weekly; Abyhankar et al. (2005), Roman et al. (2006), Di Giorgi and Post (2008), Fabian et al. (2011), Post (2008), Branda and Kopa (2014) monthly.

Because of this apparent ambiguity among most other studies, the second part of this paper deals primarily with data frequency aspect and how it influences the outcome of SSD measurements when multiple data frequencies are factored in.

\section{Theoretical Background of Stochastic Dominance}

Stochastic dominance is used for making decisions in an uncertain environment. For example, it can be equity or lottery, which has many outcome probabilities. Although there are also other types of stochastic dominance ${ }^{2}$, the first order stochastic dominance (FSD) and the second order stochastic dominance (SSD) are commonly used in finance. Their formal definitions are as follows:

2 Post and Kopa (2013) and Branda and Kopa (2016) consider the general N-th order stochastic dominance. 
If, $F_{x}(t) \leq F_{y}(t) \forall t \in R$, with strict inequality for at least one $t \in R$; then $X$ is the first order stochastically dominant ${ }^{3}$ over $Y . F_{x}(t)$ and $F_{y}(t)$ are cumulative distribution functions of $X$ and $Y$, respectively. Every non-satiated decision maker prefers $X$ over $Y$ in this case.

If, $\int_{-\infty}^{S} F_{X}(t) d t \leq \int_{-\infty}^{S} F_{y}(t) d t, \forall s \in R$, with at least one strict inequality, then $X$ is second order stochastically dominant ${ }^{4}$ over $Y$; and vice versa. $F_{x}(t)$ and $F_{y}(t)$ are cumulative probability distribution functions of $X$ and $Y$, respectively. Second order stochastic dominance is only valid for risk-averse investors ${ }^{5}$, but risk aversion is a globally used assumption by all financial markets. Portfolio managers also assume that every investor is risk-averse; therefore it is not a problem to evaluate portfolios or indexes under these circumstances.

As a mathematical fact, FSD is stronger than SSD; but it is hard to observe FSD between two financial instruments, thus SSD is used more practically. There is no need to compare the portfolio with another one by the second order stochastic dominance, since the efficiency of the portfolio can be determined without the need of a benchmark portfolio. Another advantage; there is no normal distribution requirement about the returns of the assets.

There are mainly two types of efficiency; pairwise and portfolio. If an asset is not dominated by any other possible sub-set and its all portfolio combinations with different weights, then it is called portfolio efficient. On the other hand, pairwise efficiency is that if an asset is not dominated by any other asset according to the pairwise comparisons. In other words, pairwise efficiency takes into account only the basic assets, while the portfolio efficiency takes into account all portfolios which may be created from the basic assets.

\subsection{Stochastic Dominance Pairwise Efficiency}

Following Levy (2006) let $v_{x}^{t}, t=1,2, \ldots$, T denote the ordered returns of the $x^{\text {th }}$ index in ascending order, that is, $v_{x}^{1} \leq v_{x}^{2} \leq \ldots \leq v_{x}^{T}$. Then the xth index dominates the $y^{\text {th }}$ index with respect to the first-order stochastic dominance if and only if

$$
v_{x}^{t} \geq v_{y}^{t}, t=1,2, \ldots, T \text { with at least one strict inequality. }
$$

Furthermore, $y^{\text {th }}$ index is classified as FSD pairwise inefficient if there exist some $x^{\text {th }}$ index satisfying Equation 1. Otherwise, $y^{\text {th }}$ index is FSD pairwise efficient. Thus, the algorithm of testing for the FSD pairwise efficiency of the $y^{\text {th }}$ index consists of two steps. Firstly, the returns are ordered in ascending order $v_{x}^{t}$ for all $x=1,2, \ldots, N, t=1,2, \ldots, T$. Secondly, it is tried to find some $\mathrm{x}$ satisfying Equation 1. If such $\mathrm{x}$ exists then the $y^{\text {th }}$ index is FSD pairwise inefficient. If not, then the $y^{\text {th }}$ index is FSD pairwise efficient.

Testing of SSD pairwise efficiency is performed in a similar way to the previous algorithm using criterion Equation 2 instead of Equation 1.

3 It is also referred as strict first order stochastic dominance. If strict inequality is not required, then it is called weak FSD.

4 This relation is also called strict second order stochastic dominance. If "at least one strict inequality" is relaxed, then it is named weak SSD.

5 All risk averse investors have a concave shaped utility function and SSD is valid only for this type of utility functions. 


$$
\sum_{t=1}^{S} v_{x}^{t} \geq \sum_{t=1}^{S} v_{y}^{t}, s=1,2, \ldots, T \text { with at least one strict inequality. }
$$

Additionally, an SSD pairwise efficient index is always FSD pairwise efficient. On the other hand, an FSD pairwise inefficiency implies SSD pairwise inefficiency (Branda and Kopa, 2012).

\subsection{Stochastic Dominance Portfolio Efficiency}

The main difference between portfolio efficiency and pairwise efficiency is that the investor may combine indexes with using different weights and constitute new portfolios of indexes. Thus, it is possible to use a vector of portfolio weights $\lambda=\left(\lambda_{1}, \lambda_{2}, \ldots, \lambda_{N}\right)^{\prime}$ and the portfolio possibilities are given below.

$$
\Lambda=\left\{\lambda \in R^{N} \mid 1^{\prime} \lambda=1, \lambda_{n} \geq 0, n=1,2, \ldots, N\right\} .
$$

For computational reasons attention will be given to the SSD case. SSD portfolio efficiency is defined with respect to all possible portfolios from the indexes. The $x^{\text {th }}$ index is SSD portfolio inefficient if there exists $\lambda \in \Lambda$ such that $r^{\prime} \lambda$ dominates $r_{x}$ by SSD where $r_{x}$ defines the return of the $x^{\text {th }}$ index and $r^{\prime}=\left(r_{1}, r_{2}, \ldots, r_{N}\right)$. Otherwise $x^{\text {th }}$ index is SSD portfolio efficient (Branda and Kopa, 2012).

Similarly, SSD portfolio efficiency could be defined for any portfolio $\tau \in \Lambda$, by using $r^{\prime} \tau$ instead of $r_{x}$. By using this formulation a lot of portfolio efficiency tests were formed. Some of the important ones are Post (2003), Kuosmanen (2004) and Kopa and Chovanec (2008). All of them are mentioned in Section 2 with some additional tests.

\section{Data and Method}

In this paper, stock market indexes of 33 OECD countries ${ }^{6}$ are compared by second order stochastic dominance method. Country names, indexes and Reuters index codes can be found in Table 1.

Closing values of all indexes from 31 October 2006 to 31 October 2015 are obtained from Thomson Reuters - Datastream. Pairwise the second order stochastic dominance comparisons are examined on all the indexes. There are $\left(\begin{array}{c}33 \\ 2\end{array}\right)=528$ pairwise comparisons. Data is analysed on a daily, weekly, monthly and quarterly basis individually from 31 October 2006 (for IPC index) to 31 October 2015. Due to the differentiation of holidays from country to country, there are some differences in starting days of indexes. Nonetheless, all indexes are examined for a total of 2206 working days, or 470 weeks, 108 months or 36 quarters going back from 31 October 2015. All data consisted of closing values of the indexes. Returns are obtained by the following equation for every index and date of all time frequencies.

6 Only Luxembourg out of OECD countries is excluded due to lack of data. 
Table 1 | Indexes

\begin{tabular}{|c|c|c|c|}
\hline $\begin{array}{l}\text { Country } \\
\text { Number }\end{array}$ & $\begin{array}{c}\text { Name of the OECD } \\
\text { Country }\end{array}$ & Indexes & Reuters codes \\
\hline 1 & Turkey & BIST 100 & XU100 \\
\hline 2 & Norway & Oslo Stock Exchange Equity & OBX \\
\hline 3 & Switzerland & Swiss Market & SSMI \\
\hline 4 & U.S. & S\&P 500 & SPX \\
\hline 5 & Australia & ASX All Ordinaries & AORD \\
\hline 6 & Austria & Austrian Traded & ATX \\
\hline 7 & Ireland & ISEQ Overall Price & ISEQ \\
\hline 8 & Netherlands & Amsterdam Exchanges & AEX \\
\hline 9 & Sweden & OMX Stockholm_PI & OMXSPI \\
\hline 10 & Denmark & OMX Copenhagen 20 & OMXC20 \\
\hline 11 & Canada & TSX-Toronto Stock Exchange 300 Composite & GSPTSE \\
\hline 12 & Germany & Deutsche Börse DAX & GDAXI \\
\hline 13 & Belgium & BEL 20 & $\mathrm{BFX}$ \\
\hline 14 & Finland & OMX Helsinki 25 & $\mathrm{OMXH} 25$ \\
\hline 15 & Iceland & OMX Iceland All-Share PI Equity & OMXIPI \\
\hline 16 & France & CAC 40 & $\mathrm{FCHI}$ \\
\hline 17 & United Kingdom & FTSE 100 & FTSE \\
\hline 18 & Japan & Tokyo SE JPX-Nikkei Index 400 & JPXNK400 \\
\hline 19 & Italy & FTSE Italia All-Share & FTITLMS \\
\hline 20 & New Zealand & S\&P NZX 50 Capital & NZ50 \\
\hline 21 & Spain & IBEX 35 & IBEX \\
\hline 22 & Israel & Tel Aviv 100 & TA100 \\
\hline 23 & South Korea & Korea SE Kospi & KS11 \\
\hline 24 & Slovenia & Ljubljana Stock Exchange SBI TOP & SBITOP \\
\hline 25 & Czech Republic & PX Prague SE & $\mathrm{PX}$ \\
\hline 26 & Greece & Athex General Composite Share Price & ATG \\
\hline 27 & Slovakia & SAX & SAX \\
\hline 28 & Portugal & PSI All Share Gross Return & BVLG \\
\hline 29 & Estonia & OMX Talinn_GI & OMXTGI \\
\hline 30 & Poland & Warsaw SE WIG Poland & WIG \\
\hline 31 & Hungary & Budapest SE & BUX \\
\hline 32 & Chile & IPSA & IPSA \\
\hline 33 & Mexico & IPC & $M X X$ \\
\hline
\end{tabular}

Source: Thomson Reuters Eikon Database. 


$$
v_{x}^{t}=\frac{c_{x}^{t^{+}+1}-c_{x}^{t}}{c_{x}^{t}} ; t=1,2, \ldots, T, x=1,2, \ldots, N
$$

$C$... closing value of the $x^{\text {th }}$ index at the $t^{\text {th }}$ period,

$T$... number of periods $N$ : Number of Indexes.

After obtaining the returns for each index, cumulative distribution functions ${ }^{7}$ are found. Every observation is equally weighted, which means the probability of each observation is $1 / 2206$ for daily, $1 / 470$ for weekly, $1 / 108$ for monthly and 1/36 for quarterly. In Excel, returns of both compared indexes are sorted from the lowest to the highest return with respect to their corresponding probabilities.

Last step is to check, if there is SSD or not. There are 33 indexes, which required $\left(\begin{array}{c}33 \\ 2\end{array}\right)=528$ pairwise comparisons for each data frequency. Due to time consuming nature of manual calculations, $4 * 528=2,112$ pairwise comparisons are processed by a computer. A proprietary algorithm in $\mathrm{C}++$ is developed to check these SSD relations among pairs by using cumulative distributions and returns. The working principle of this algorithm is based on Equation 2.

All the country indexes are categorized according to the pairwise SSD comparisons of indexes. The related categories can be found below:

A: The indexes which dominate at least one index and are not dominated by any other index.

$\mathrm{B}$ : The indexes which are dominated by at least one stock and do not dominate any other index.

$\mathrm{C}$ : The indexes which are dominated by at least one index and dominate at least one other index.

D: The indexes which are not dominated by any index and do not dominate any other index.

Indexes which are not dominated by any other index are identified and labelled as SSD pairwise efficient. On the other hand, indexes which are dominated by at least one other index are identified as SSD pairwise inefficient. In other words, indexes in the groups of A\&D are SSD pairwise efficient and indexes in the groups of B\&C are SSD pairwise inefficient.

In this paper, in addition to the SSD pairwise efficiency, a more powerful test, an SSD pairwise efficiency test with enriched set of assets (ESA) is also conducted. Since portfolio SSD efficiency tests may be computationally intractable because of the infinite number of portfolio combinations and large number of observations (especially for daily data), an enriched set of 33 portfolios are created in the following way:

Let $\mathrm{A} 1$ is the index with the highest mean return and $A_{2}, \ldots, A_{33}$ are the other indexes. 33 additional portfolios with $P_{j}=0.5 A_{1}+0.5 A_{j}$, for all $j=2, \ldots, 33$ and $P_{34}=\left(A_{1}+A_{2}+\ldots+\right.$ $\left.+A_{33}\right) / 33$ are constructed and pairwise SSD efficiency is tested with respect to this enriched set of assets (including 33 indexes and 33 additional created portfolios $P_{j}, j=2, \ldots, 34$ ). An index which is not dominated by any other index, as well as, not by any other additional

$7 \quad$ It is obvious that the findings of this study depend on the sample and its related distribution functions. This relationship, as well as the empirical estimates of stochastic optimization, is examined in the papers of Kankova and Houda (2015) and Kankova and Omelchenko (2015). 
portfolio is called as SSD pairwise efficient with enriched set of assets (ESA). At this point it must be underlined, there is still a possibility that any other portfolio, which is not from the created 33 portfolios, can still second orderly dominate an SSD pairwise efficient index with ESA. Obviously an index is SSD pairwise efficient if it is SSD pairwise efficient with respect to ESA, since SSD pairwise efficiency is a subset of SSD pairwise efficiency with ESA. To check the SSD pairwise efficient indexes with ESA, an additional 2,112 pairwise comparisons are calculated with the help of $\mathrm{C}++$ algorithm.

\section{Results}

According to the results, SSD pairwise comparison matrices are obtained. These matrices displayed in the Appendix A state comparisons of 33 OECD country indexes with each other and also with ESA for each data frequency. With the help of these matrices, the 33 countries are classified into the groups A, B, C, and D for four different data frequencies with and without ESA. It is obvious that the category "Dominates" stands for A, "Dominated" for B, "Dominates and Dominated" for C and "Neither Dominates nor Dominated" for D. Since there are two efficiency tests; the first SSD pairwise without ESA, the second SSD pairwise with ESA; some indexes which are marked with the arrow move from A to C in the latter one. As an interesting finding, none of the country indexes belongs to the cluster $\mathrm{D}$ in any data frequency. Following Figures 1 - Figure 4 illustrate these clusters for each data frequency in the shape of Venn diagrams.

Figure 1 | Daily SSD Pairwise Efficient (with and without ESA) Countries

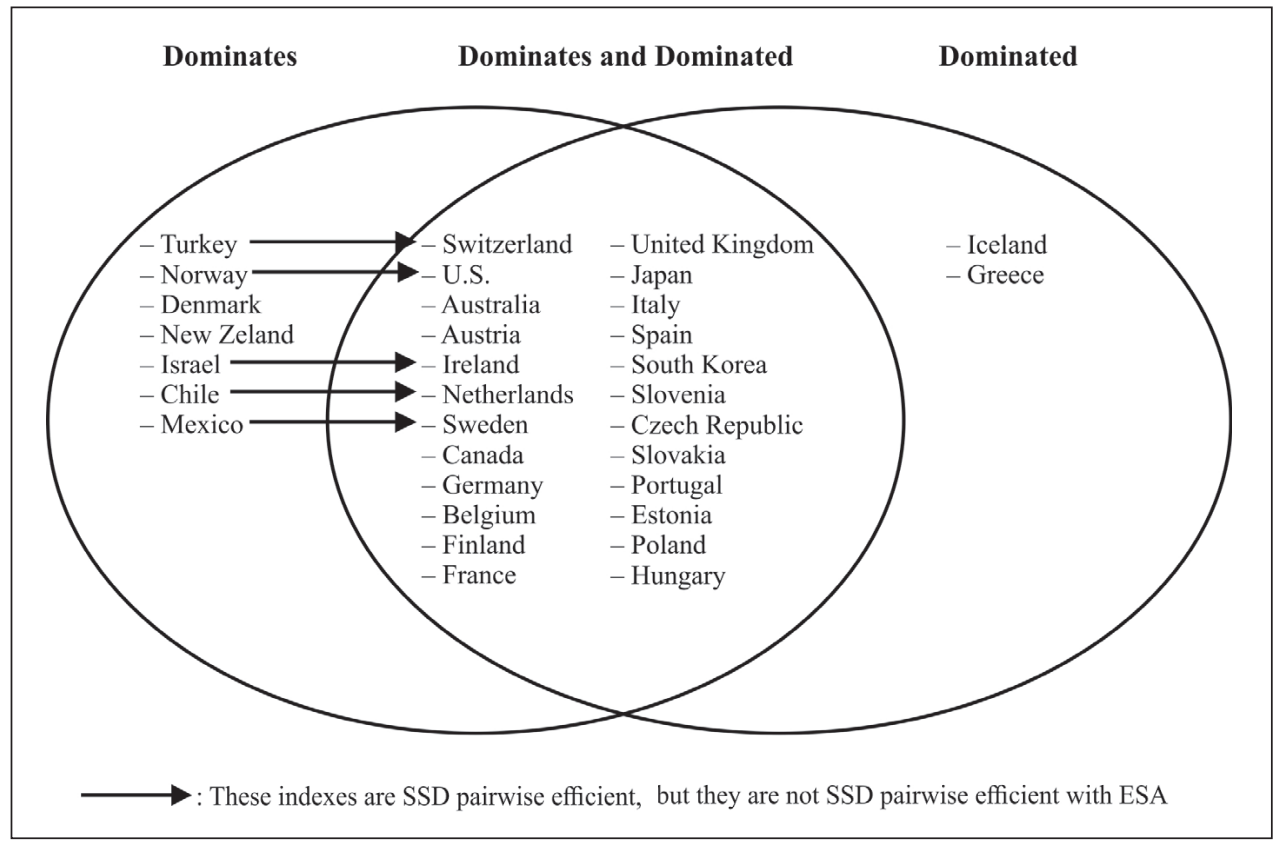

Source: Authors' own computations. 
Figure 2 | Weekly SSD Pairwise Efficient (with and without ESA) Countries

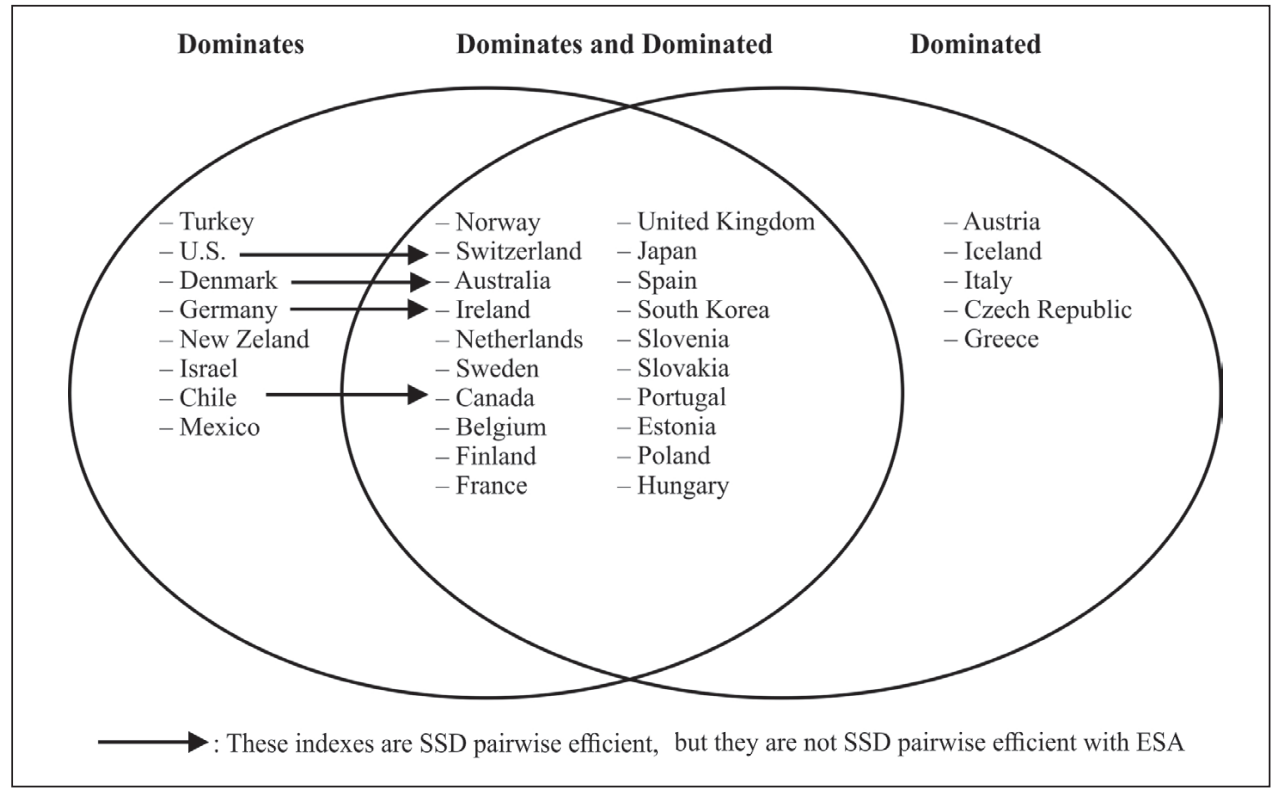

Source: Authors' own computations.

Figure 3 | Monthly SSD Pairwise Efficient (with and without ESA) Countries

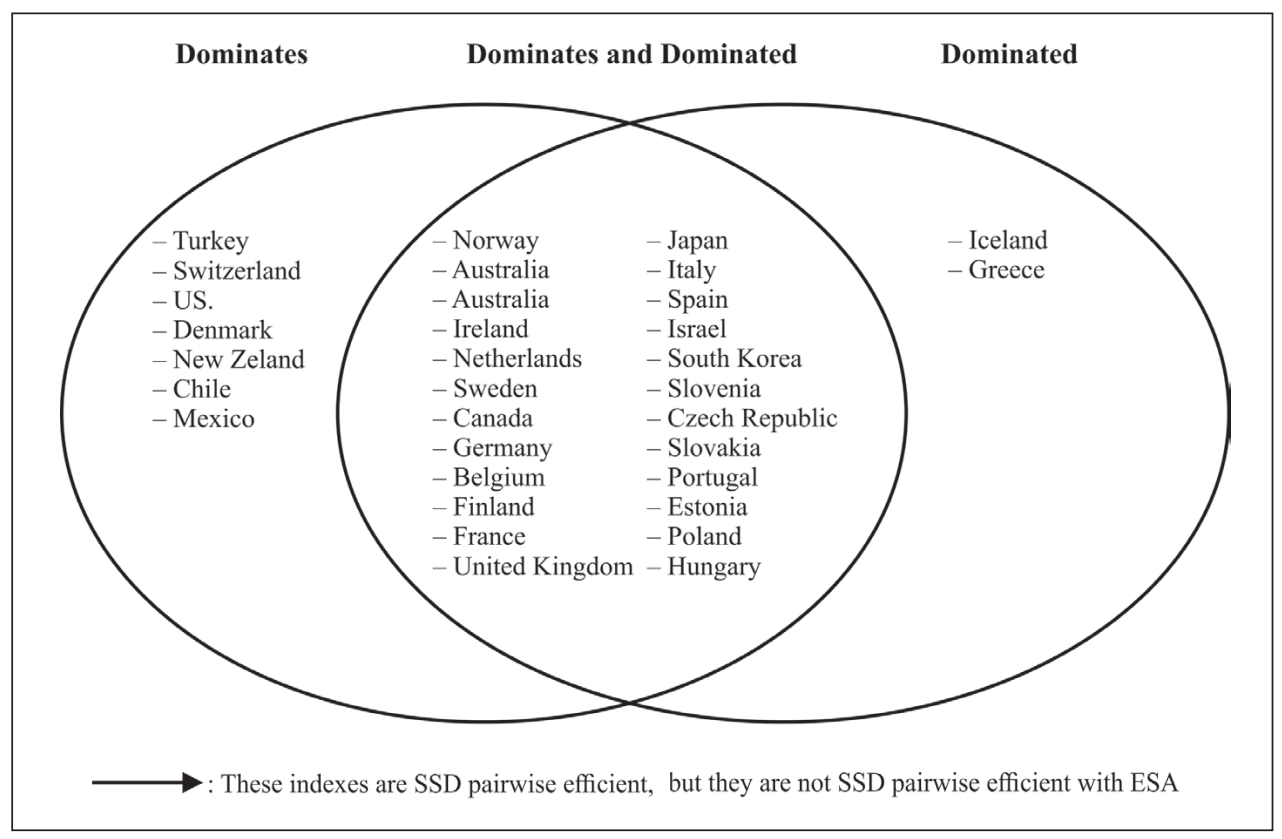

Source: Authors' own computations. 


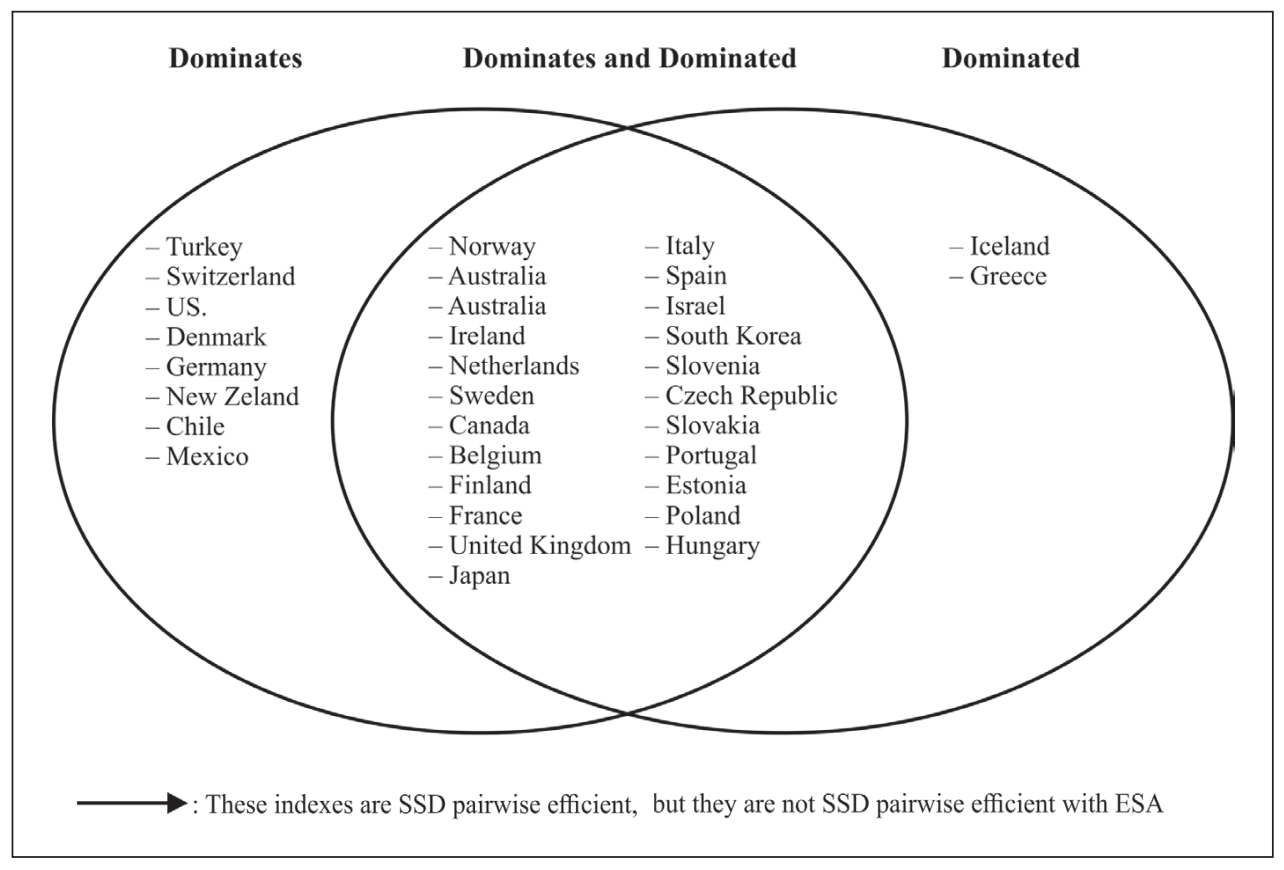

Source: Authors' own computations.

Following Table 2 and Figure 5 display the results of two SSD pairwise efficiency tests for each data frequency in a summarized manner.

Within the scope of this paper, analysis of SSD pairwise efficiencies (both with and without ESA) of 33 OECD countries and calculation of the effects of multiple data frequencies in these SSD efficiency tests are successfully implemented. The most important findings of the Table 2 and Figure 5 are stated below.

According to Table 2, two third of the OECD countries (22 of 33) are neither SSD pairwise efficient nor SSD pairwise with ESA efficient for each data frequency. Furthermore, Turkey, Denmark, New Zealand, Chile and Mexico are the best performing country indexes since they are SSD pairwise efficient in each data frequency.

According to Figure 5, in the daily data frequency only $28.5 \%$ (2 of 7 ) of the SSD pairwise efficient indexes are also SSD pairwise efficient with ESA; in the weekly data frequency, this proportion is $50 \%$ (4 of 8 ). On the other hand, in the monthly and quarterly data frequencies, this percentage is $100 \%$ (7 of 7 and 8 of 8). Because of that in Figure 3 and Figure 4 , there is not any observation of arrows which move country indexes from group A to $\mathrm{C}$. 
Table 2 | Summary of SSD Pairwise Efficiency Tests of the 33 OECD Country Indexes for Each Data Frequency

\begin{tabular}{|c|c|c|c|c|c|c|c|c|c|}
\hline & \multicolumn{2}{|c|}{ Daily } & \multicolumn{2}{|c|}{ Weekly } & \multicolumn{2}{|c|}{ Monthly } & \multicolumn{2}{|c|}{ Quarterly } \\
\hline & & $\begin{array}{l}\text { Pairwise } \\
\text { Efficient }\end{array}$ & $\begin{array}{l}\text { Pairwise } \\
\text { Efficient } \\
\text { with ESA }\end{array}$ & $\begin{array}{l}\text { Pairwise } \\
\text { Efficient }\end{array}$ & $\begin{array}{l}\text { Pairwise } \\
\text { Efficient } \\
\text { with ESA }\end{array}$ & $\begin{array}{l}\text { Pairwise } \\
\text { Efficient }\end{array}$ & $\begin{array}{l}\text { Pairwise } \\
\text { Efficient } \\
\text { with ESA }\end{array}$ & $\begin{array}{l}\text { Pairwise } \\
\text { Efficient }\end{array}$ & $\begin{array}{l}\text { Pairwise } \\
\text { Efficient } \\
\text { with ESA }\end{array}$ \\
\hline 1 & Turkey & $\checkmark$ & & $\checkmark$ & $\checkmark$ & $\checkmark$ & $\checkmark$ & $\checkmark$ & $\checkmark$ \\
\hline 2 & Norway & $\checkmark$ & & & & & & & \\
\hline 3 & Switzerland & & & & & $\checkmark$ & $\checkmark$ & $\checkmark$ & $\checkmark$ \\
\hline 4 & U.S. & & & $\checkmark$ & & $\checkmark$ & $\checkmark$ & $\checkmark$ & $\checkmark$ \\
\hline 5 & Australia & & & & & & & & \\
\hline 6 & Austria & & & & & & & & \\
\hline 7 & Ireland & & & & & & & & \\
\hline 8 & Netherlands & & & & & & & & \\
\hline 9 & Sweden & & & & & & & & \\
\hline 10 & Denmark & $\checkmark$ & $\checkmark$ & $\checkmark$ & & $\checkmark$ & $\checkmark$ & $\checkmark$ & $\checkmark$ \\
\hline 11 & Canada & & & & & & & & \\
\hline 12 & Germany & & & $\checkmark$ & & & & $\checkmark$ & $\checkmark$ \\
\hline 13 & Belgium & & & & & & & & \\
\hline 14 & Finland & & & & & & & & \\
\hline 15 & Iceland & & & & & & & & \\
\hline 16 & France & & & & & & & & \\
\hline 17 & $\begin{array}{l}\text { United } \\
\text { Kingdom }\end{array}$ & & & & & & & & \\
\hline 18 & Japan & & & & & & & & \\
\hline 19 & Italy & & & & & & & & \\
\hline 20 & New Zealand & $\checkmark$ & $\checkmark$ & $\checkmark$ & $\checkmark$ & $\checkmark$ & $\checkmark$ & $\checkmark$ & $\checkmark$ \\
\hline 21 & Spain & & & & & & & & \\
\hline 22 & Israel & $\checkmark$ & & $\checkmark$ & $\checkmark$ & & & & \\
\hline 23 & South Korea & & & & & & & & \\
\hline 24 & Slovenia & & & & & & & & \\
\hline 25 & Czech Republic & & & & & & & & \\
\hline 26 & Greece & & & & & & & & \\
\hline 27 & Slovakia & & & & & & & & \\
\hline 28 & Portugal & & & & & & & & \\
\hline 29 & Estonia & & & & & & & & \\
\hline 30 & Poland & & & & & & & & \\
\hline 31 & Hungary & & & & & & & & \\
\hline 32 & Chile & $\checkmark$ & & $\checkmark$ & & $\checkmark$ & $\checkmark$ & $\checkmark$ & $\checkmark$ \\
\hline 33 & Mexico & $\checkmark$ & & $\checkmark$ & $\checkmark$ & $\checkmark$ & $\checkmark$ & $\checkmark$ & $\checkmark$ \\
\hline
\end{tabular}

Source: Authors' own computations. 


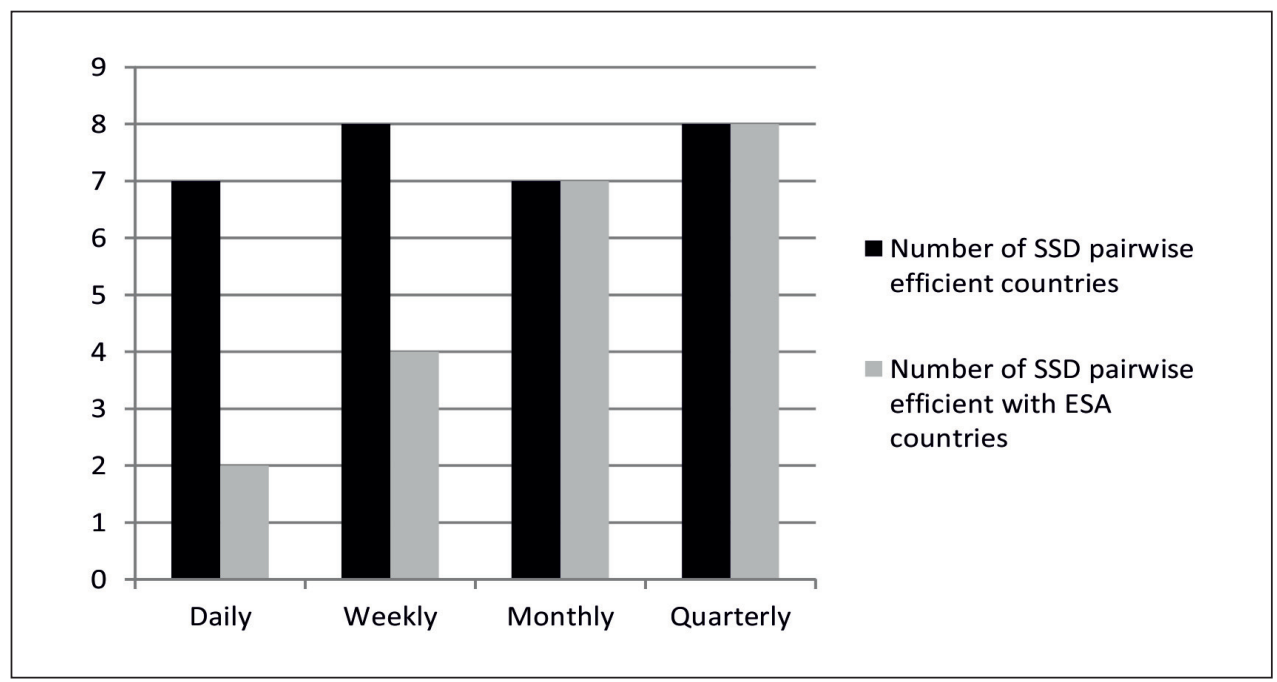

Source: Authors' own computations.

\section{Conclusions}

The most important contributions of this study to the literature can be summarized in three points.

Firstly, a very serious proportion of the OECD countries are neither SSD pairwise efficient nor SSD pairwise efficient with ESA. Interestingly, the three of the five best performing OECD countries; Turkey, Chile, Mexico have the lowest GDP (PPP) per capita level ${ }^{8}$ among the all OECD countries.

Secondly, these findings above also prove that the SSD efficient set is data frequency sensitive and the results begin to alter if the density of the data decreases. It is not possible to suggest only one data frequency for every investor since the choice of the data frequency is dependent on the investor type. A short-run investor who trades in daily basis should prefer daily data frequency; on the other hand, a long-run investor can prefer a lower data frequency such as weekly, monthly or even quarterly.

Thirdly, when the data frequency is lowered, the difference between two SSD pairwise efficiency tests decreases and it converges to zero. The dilution in the data which causes diminishing volatility could be an underlying reason for this situation.

Additionally, the Table B-1 in the Appendix B ranks the OECD country indexes according to the Sharpe Ratio as a traditional measurement method for each data frequency. The top ranking countries in this table are correspondent with the results of above findings in Table 2.

In the future, in light of these findings, stocks that make up these indexes can be analysed within the confines of their respective indexes. It gives the possibility to invest 
in a portfolio from different countries, which will decrease the market risk. Furthermore, returns on different index portfolios can be simulated and the performance of the chosen portfolios in this paper can be evaluated for different time frames.

\section{Appendix A}

Following matrices show the results of different data frequencies; daily, weekly, and monthly, respectively. "1", highlighted by dark gray colour, represents that the first index, which is in the row, the second orderly stochastic dominates the second index, which is in the column. "2", highlighted by light gray colour, represents that the second index, second orderly stochastic dominates the first index. "-", highlighted by no colour, represents that there is no second order stochastic dominance relationship between the indexes. For each data frequency, there are two matrices; the first one shows the pairwise comparisons of 33 OECD countries $j(j=1,2, \ldots, 33)$ with each other and the second one displays the pairwise comparisons between 33 OECD countries and the 33 created portfolios $P_{j}(j=1$, $2, \ldots, 33)$. The first matrix is used for detection of the SSD pairwise efficiency while the second one determines the SSD portfolio efficiency. For each data frequency, the matrices in Table A. 1 - Table A. 8 are as follows. 
Table A-1 | Daily SSD Pairwise Comparison Matrix (33 OECD countries with each other)

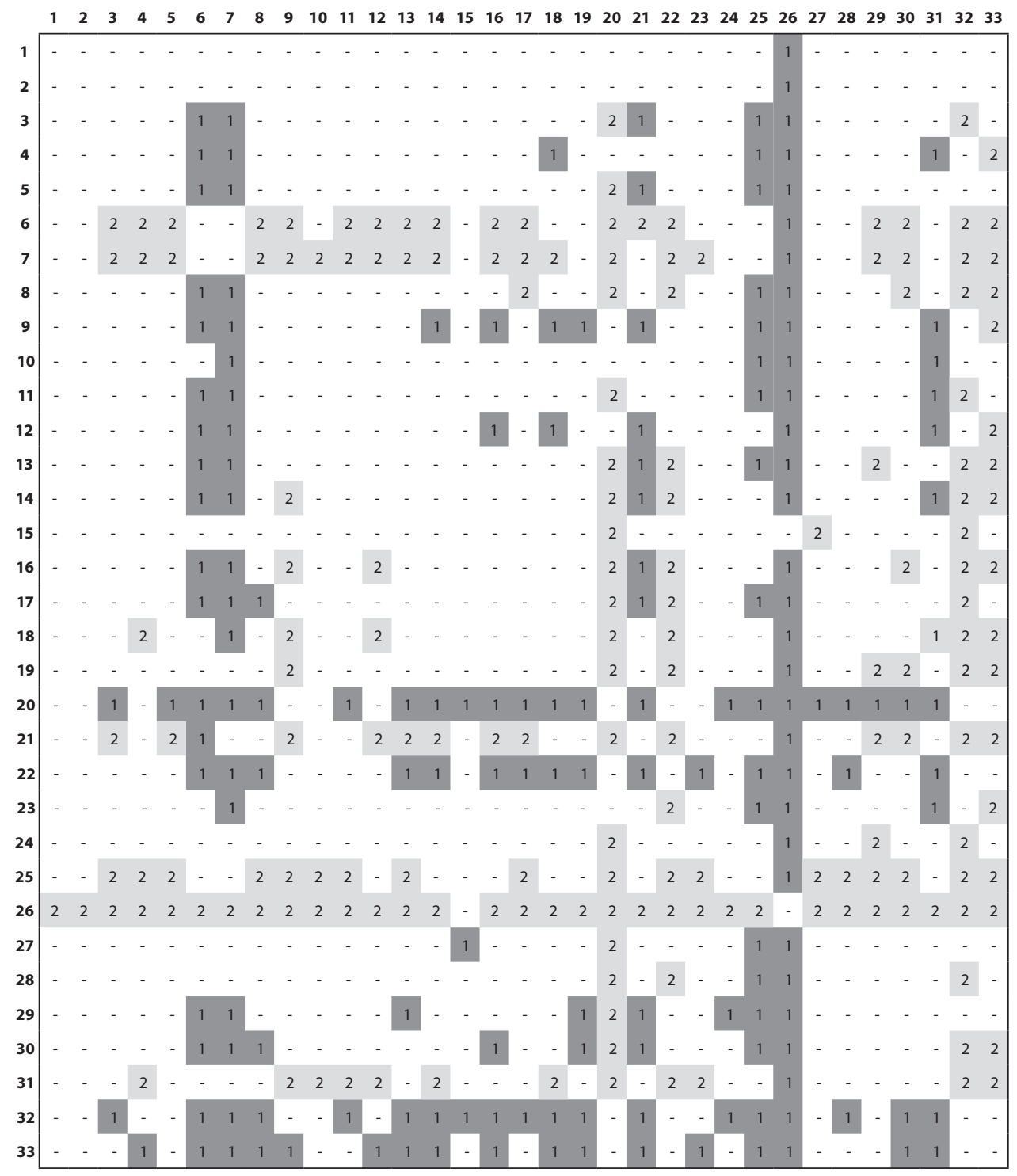

Source: Authors' own computations. 
Table A-2 | Daily SSD Pairwise Comparison Matrix (33 OECD countries vs 33 portfolios)

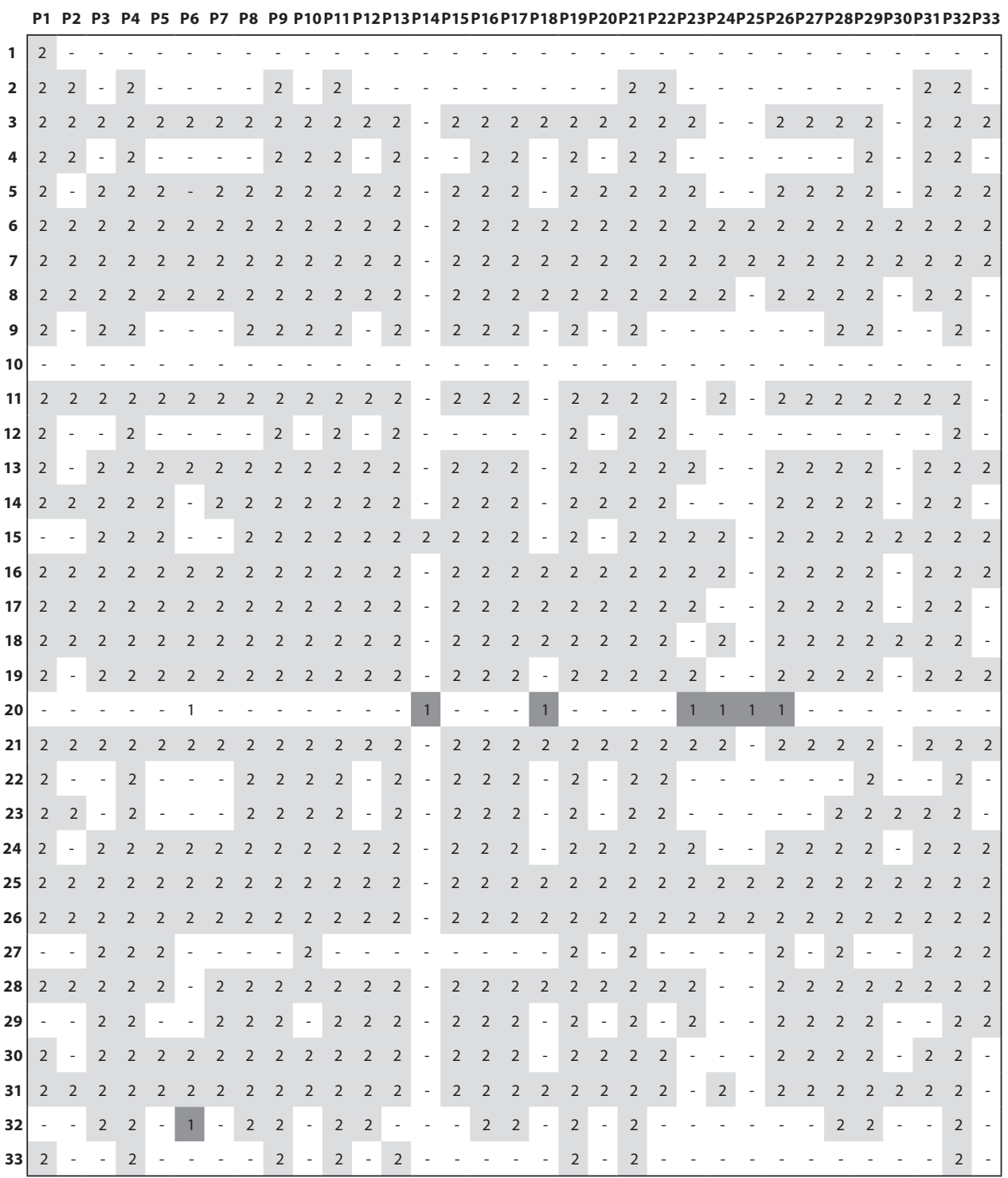

Source: Authors' own computations. 
Table A-3 | Weekly SSD Pairwise Comparison Matrix (33 OECD countries with each other)

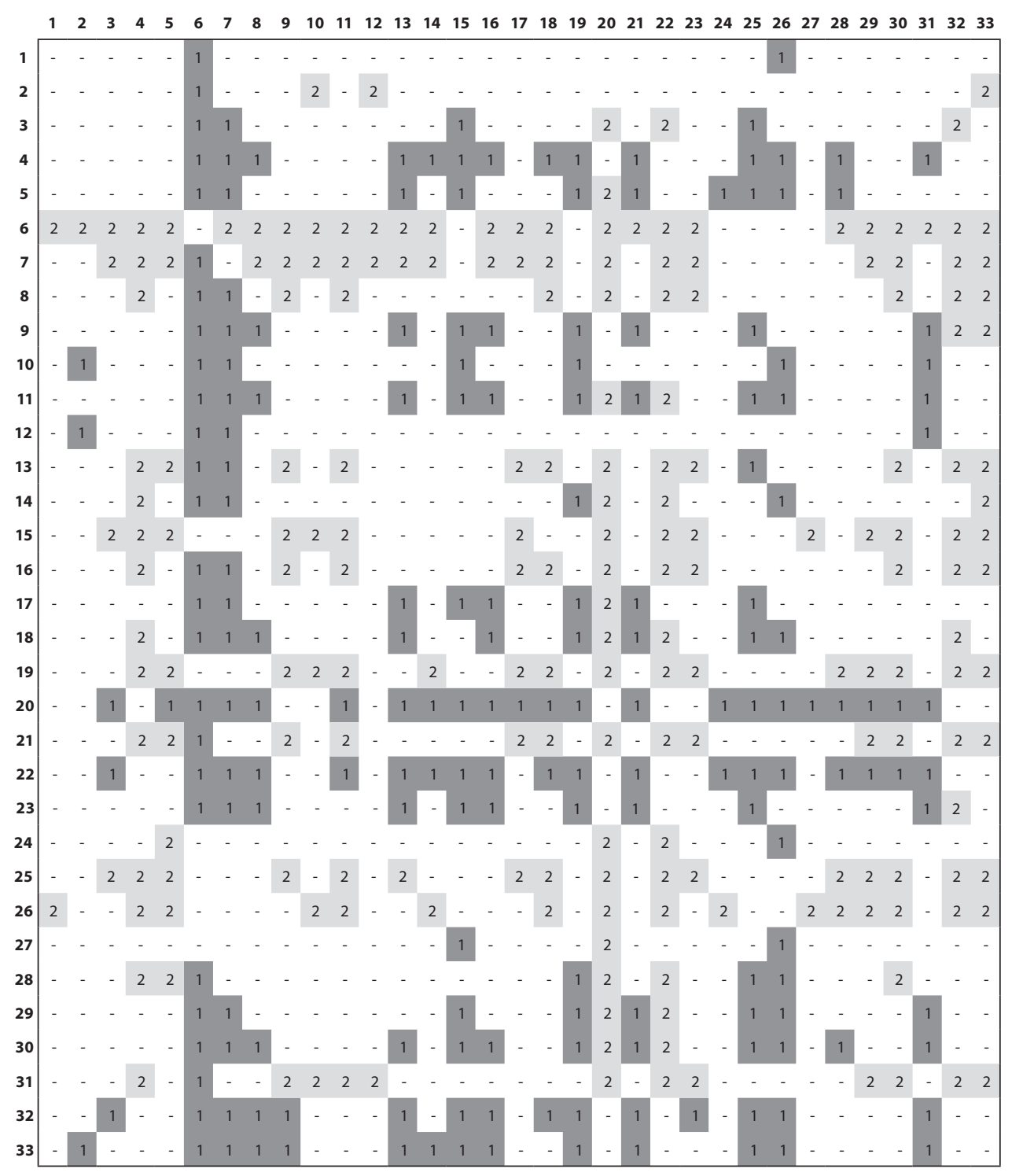

Source: Authors' own computations. 
Table A-4 | Weekly SSD Pairwise Comparison Matrix (33 OECD countries vs 33 portfolios)

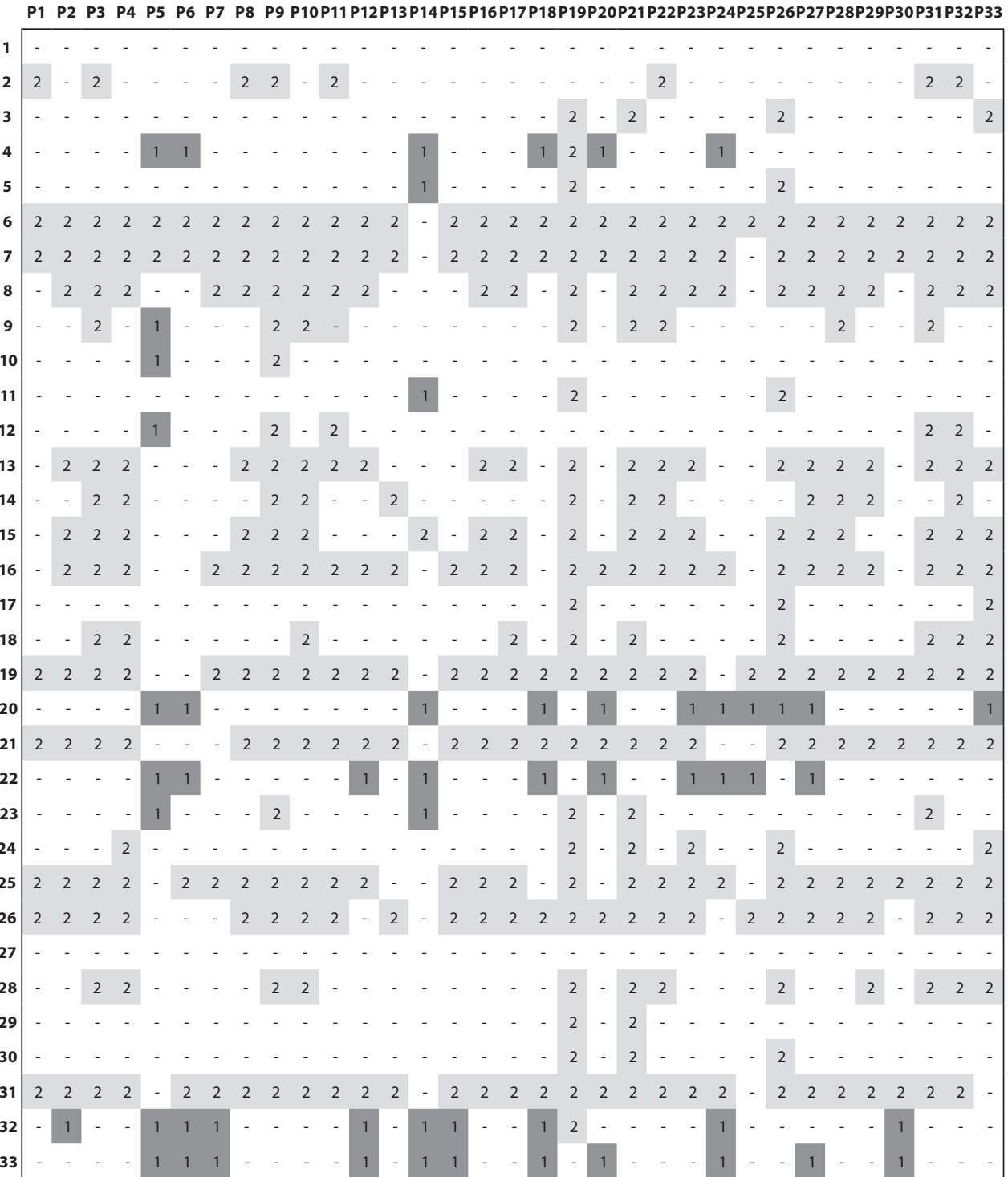

Source: Authors' own computations. 
Table A-5 | Monthly SSD Pairwise Comparison Matrix (33 OECD countries with each other)

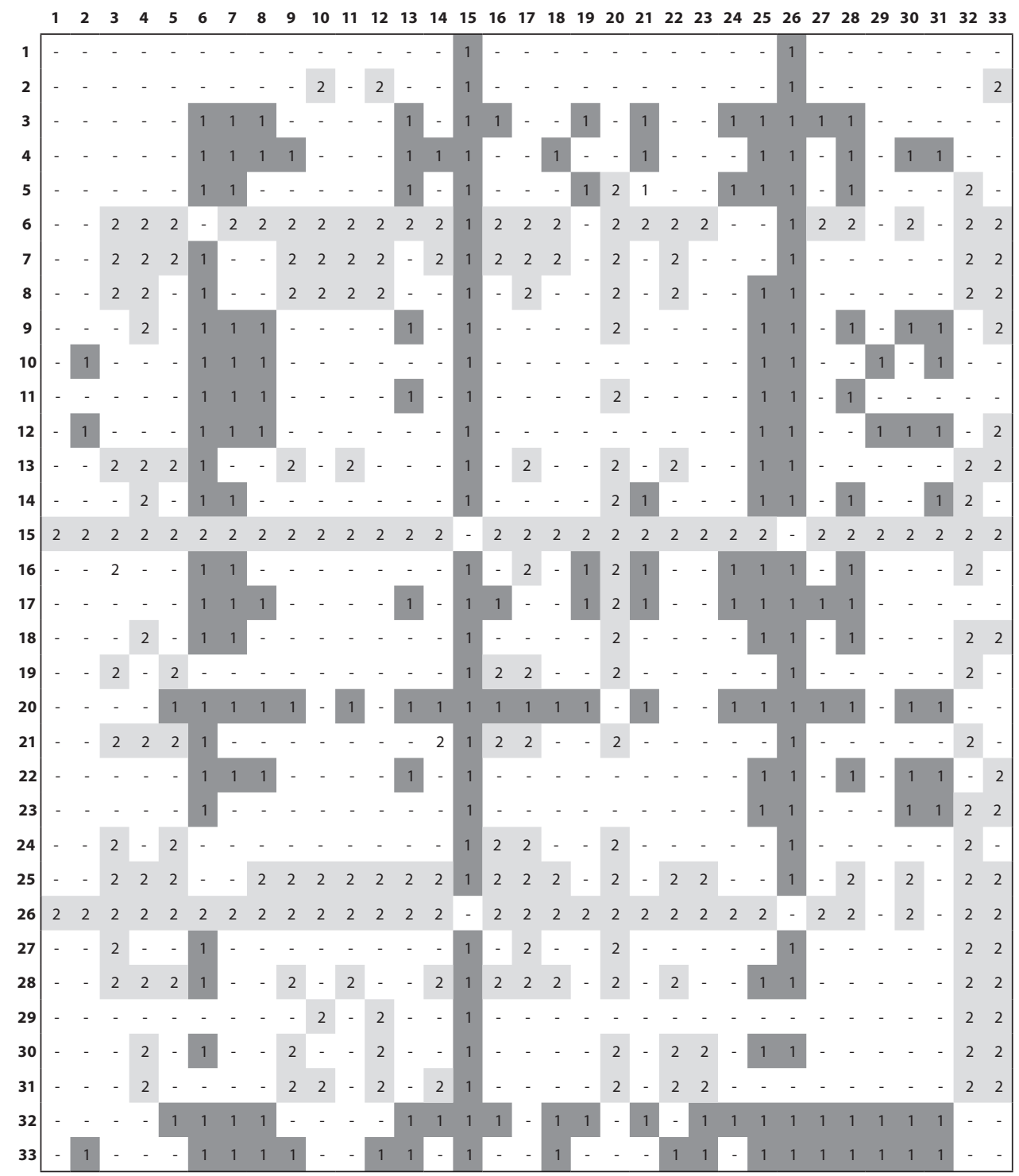

Source: Authors' own computations. 
Table A-6 | Monthly SSD Pairwise Comparison Matrix (33 OECD countries vs 33 portfolios)

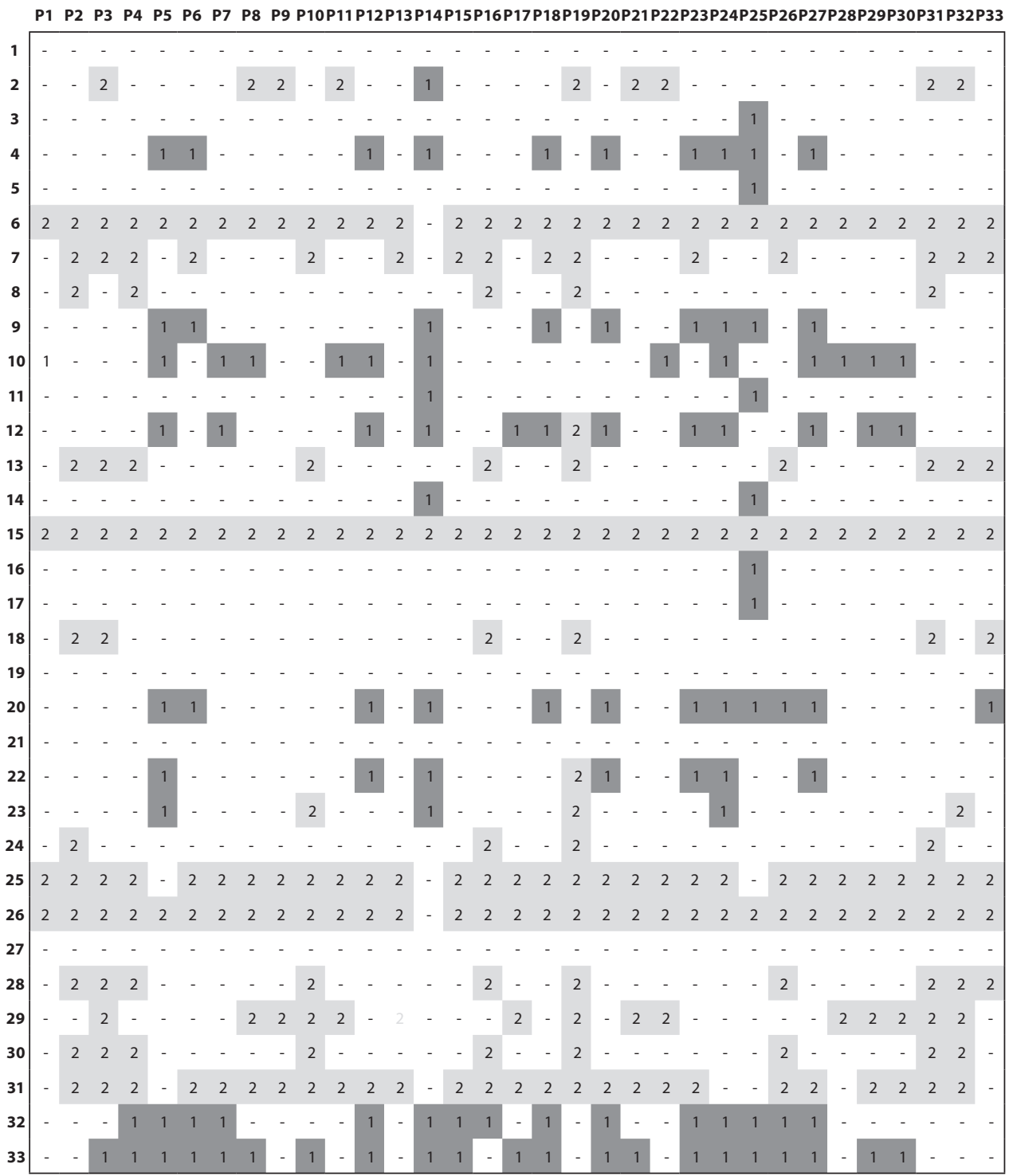

Source: Authors' own computations. 
Table A-7 | Quarterly SSD Pairwise Comparison Matrix (33 OECD countries with each other)

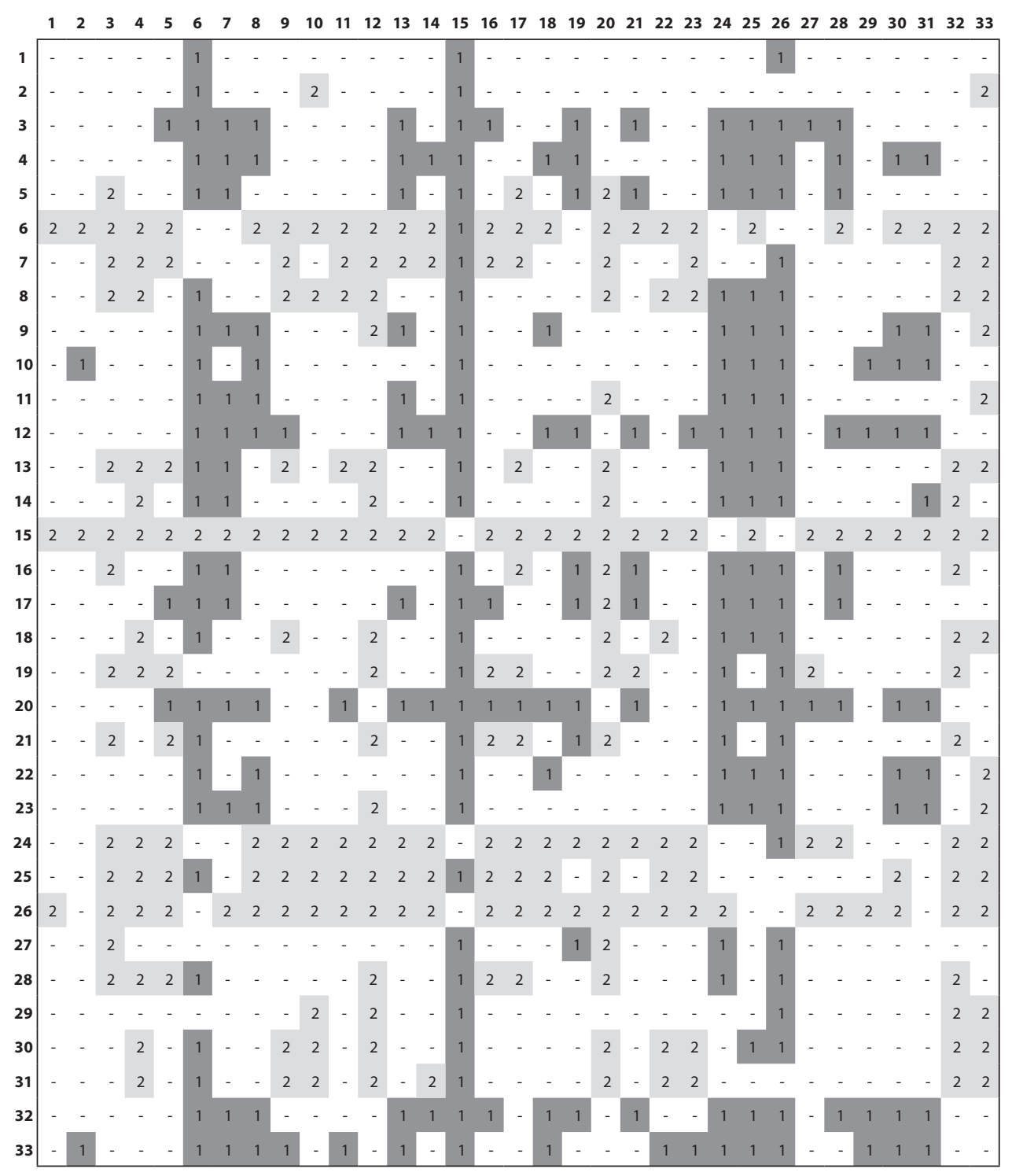

Source: Authors' own computations. 


\section{Table A-8 | Quarterly SSD Pairwise Comparison Matrix (33 OECD countries vs 33 portfolios)}

P1 P2 P3 P4 P5 P6 P7 P8 P9 P10P11 P12P13 P14P15P16P17P18P19P20P21P22P23P24P25P26P27P28P29P30P31P32P33

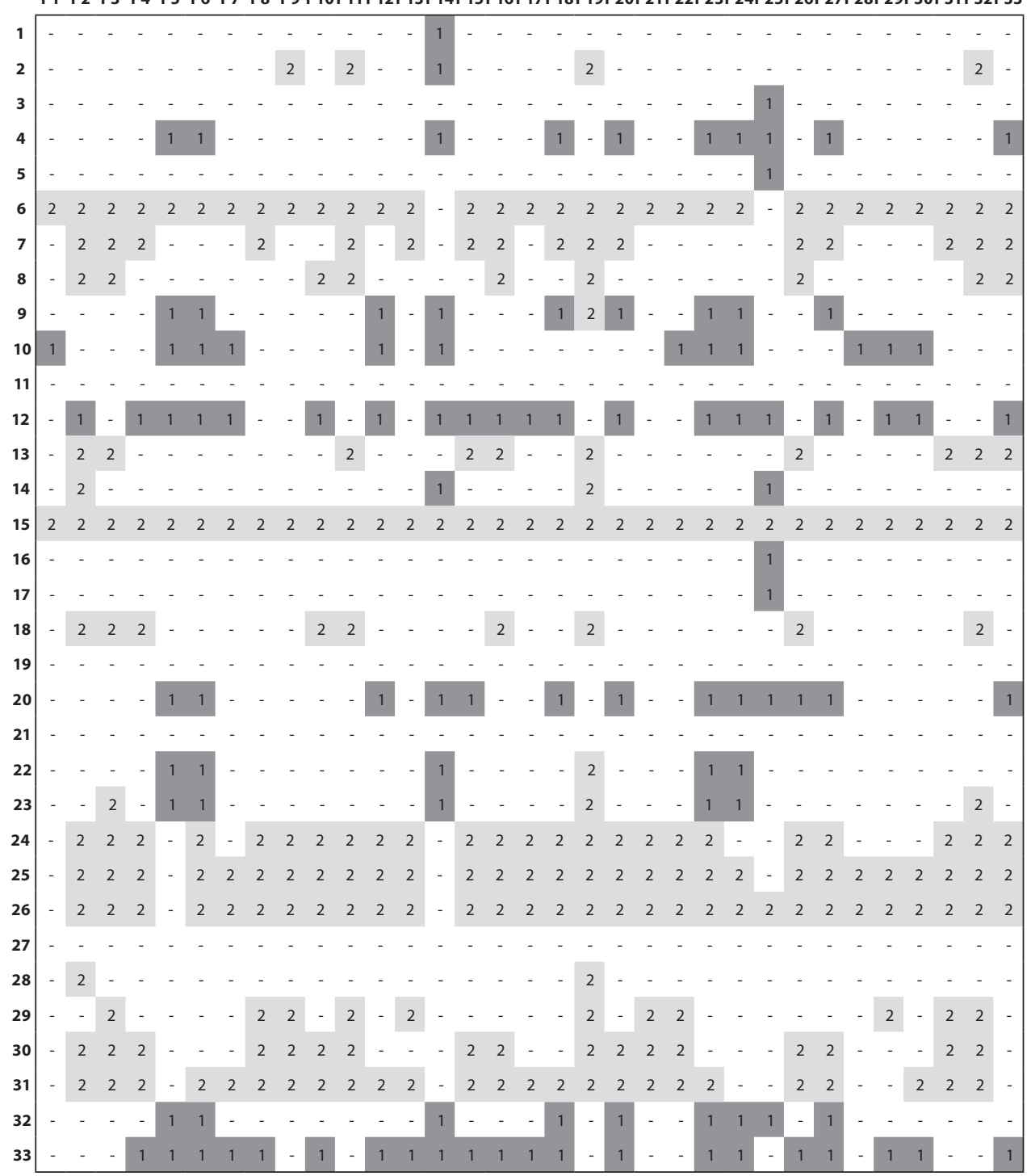

Source: Authors' own computations.

\section{Appendix B}

Following Table B-1 displays the ranking of 33 OECD country indexes according to the Sharpe Ratio ${ }^{9}$ for each data frequency.

9 By the calculation of the Sharpe Ratio, the risk free rate is assumed as zero to standardize the process, since this rate radically changes from country to country. 
Table B-1 | Ranking of 33 OECD Country Indexes according to the Sharpe Ratio for Each Data Frequency

\begin{tabular}{|c|c|c|c|c|}
\hline Rank & Daily & Weekly & Monthly & Quarterly \\
\hline 1 & Denmark & Denmark & Denmark & Denmark \\
\hline 2 & New Zealand & New Zealand & Mexico & Mexico \\
\hline 3 & Turkey & Mexico & New Zealand & New Zealand \\
\hline 4 & Mexico & Turkey & Germany & Germany \\
\hline 5 & Israel & Germany & Turkey & Turkey \\
\hline 6 & Chile & Chile & Chile & U.S \\
\hline 7 & Germany & Israel & U.S & Chile \\
\hline 8 & Norway & Norway & Norway & Norway \\
\hline 9 & U.S. & U.S. & Israel & Israel \\
\hline 10 & South Korea & South Korea & South Korea & South Korea \\
\hline 11 & Sweden & Sweden & Sweden & Sweden \\
\hline 12 & Finland & Finland & Estonia & Estonia \\
\hline 13 & Canada & Estonia & Finland & Finland \\
\hline 14 & Japan & Canada & Canada & Canada \\
\hline 15 & Poland & Poland & Poland & Poland \\
\hline 16 & United Kingdom & United Kingdom & Japan & Japan \\
\hline 17 & Hungary & Switzerland & Hungary & Hungary \\
\hline 18 & Netherlands & Japan & Switzerland & Switzerland \\
\hline 19 & Switzerland & Hungary & United Kingdom & United Kingdom \\
\hline 20 & Estonia & Netherlands & Netherlands & Netherlands \\
\hline 21 & France & Australia & Australia & Australia \\
\hline 22 & Australia & France & France & France \\
\hline 23 & Spain & Belgium & Belgium & Belgium \\
\hline 24 & Belgium & Ireland & Ireland & Ireland \\
\hline 25 & Ireland & Spain & Spain & Portugal \\
\hline 26 & Austria & Portugal & Portugal & Spain \\
\hline 27 & Portugal & Austria & Czech Republic & Austria \\
\hline 28 & Czech Republic & Italy & Austria & Czech Republic \\
\hline 29 & Slovakia & Czech Republic & Italy & Iceland \\
\hline 30 & Italy & Slovakia & Slovakia & Slovenia \\
\hline 31 & Iceland & Slovenia & Iceland & Italy \\
\hline 32 & Slovenia & Iceland & Slovenia & Slovakia \\
\hline 33 & Greece & Greece & Greece & Greece \\
\hline
\end{tabular}

Source: Authors' own computations. 


\section{References}

Abyankhar, A., Ho, K. Y., Zhao, H. (2005). Long-Run Post-Merger Stock Performance of UK Acquiring Firms: A Stochastic Dominance Perspective. Applied Financial Economics, 15(10), 679-690, https://doi.org/10.1080/09603100500065305

Al-Khazali, O., Lean, H. H., Samet, A. (2014). Do Islamic Stock Indexes Outperform Conventional Stock Indexes? A Stochastic Dominance Approach. Pacific-Basin Finance Journal, 28, 29-46, https://doi.org/10.1016/j.pacfin.2013.09.003

Best, R. J., Best, R. W., Yoder, J. A. (2000). Value Stocks and Market Efficiency. Journal of Economics and Finance, 24(1), Spring 2000, 28-35, https://doi.org/10.1007/BF02759693

Branda, M., Kopa, M. (2012). DEA-Risk Efficiency and Stochastic Dominance Efficiency of Stock Indexes. Czech Journal of Economics and Finance, 62(2), 106-124.

Branda, M., Kopa, M. (2014). On Relations between DEA-Risk Models and Stochastic Dominance Efficiency Tests. Central European Journal of Operations Research, 22(1), 13-35, https://doi.org/10.1007/s10100-012-0283-2

Branda, M., Kopa, M. (2016). DEA Models Equivalent to General N-th Order Stochastic Dominance Efficiency Tests. Operations Research Letters, 44(2), 285-289, https://doi.org/10.1016/j.orl.2016.02.007

De Giorgi, E., Post, T. (2008). Second-Order Stochastic Dominance, Reward-Risk Portfolio Selection, and the CAPM. Journal of Financial and Quantitative Analysis, 43(2), June 2008, 525-546, https://doi.org/ http://dx.doi.org/10.1017/S0022109000003616

Dupacova, J., Kopa, M. (2012). Robustness in Stochastic Programs with Risk Constraints. Annals of Operations Research, 200(1), 55-74, https://doi.org/10.1007/s10479-010-0824-9

Elton, E. J., Gruber, M. J. (1997). Modern Portfolio Theory, 1950 to Date. Journal of Banking \& Finance, 21(11-12), 1743-1759, https://doi.org/10.1016/S0378-4266(97)00048-4

Fabian, I. C., Mitra, G., Roman, D., Zverovich, V. (2011). An Enhanced Model for Portfolio Choice with SSD Criteria: a Constructive Approach. Quantitative Finance, 11(10), October 2011, 1525-1534, https://doi.org/10.1080/1469768090349360

Fong, W. M. (2009). Speculative Trading and Stock Returns: A Stochastic Dominance Analysis of the Chinese A-Share Market. Journal of International Financial Markets, Institutions \& Money, 19(4), 712-727, https://doi.org/10.1016/j.intfin.2008.12.003

Grechuk, B. (2014). A Simple SSD-Efficiency Test. Optimization Letters, 8(7), 2135-2143, https://doi.org/10.1007/s11590-013-0720-8

Güran, C. B., Tas, O., Güran, A. (2013). Second Order Stochastic Dominance Efficiency Test of a Portfolio - An Empirical Study on the BIST-30 Index. Paper presented at the IISRO Conference Dubai.

Güran, C. B., Tas, O. (2015). Making Second Order Stochastic Dominance İnefficient Mean Variance Portfolio Efficient: Application in Turkish BIST-30 Index. Iktisat Isletme ve Finans, 30(348), 69-94, https://doi.org/10.3848/iif.2015.348.4338

Hanoch, G., Levy, H. (1969). The Efficiency Analysis of Choices Involving Risk. Review of Economic Studies, 36(3), 335-346, https://doi.org/10.2307/2296431

Hodder, J. E., Jackwerth, J. C., Kolokolova, O. (2015). Improved Portfolio Choice Using Second-Order Stochastic Dominance. Review of Finance, 19(4), 1623-1647, https://doi.org/10.1093/rof/rfu025

Jensen, M. C. (1968). The Performance of Mutual Funds in the Period 1945-1964. Journal of Finance, 23(2), 389-416, https://doi.org/10.1111/j.1540-6261.1968.tb00815.x 
Kankova, V., Houda, M. (2015). Thin and Heavy Tails in Stochastic Programming. Kybernetika, 51(3), 433-456, https://doi.org/10.14736/kyb-2015-3-0433

Kankova V., Omelchenko, V. (2015). Empirical Estimates in Stochastic Programs with Probability and Second Order Dominance Constraints. Acta Mathematica Universitatis Comenianae. 84(2), 267-281.

Kopa, M., Chovanec, P. (2008). A Second-Order Stochastic Dominance Portfolio Efficiency Measure. Kybernetika, 44(2), 243-258.

Kopa, M., Post, T. (2009). A Portfolio Optimality Test Based on the First-Order Stochastic Dominance Criterion. Journal of Financial and Quantitative Analysis, 44(5), 1103-1124, https://doi.org/10.1017/S0022109009990251

Kopa, M., Post, T. (2015). A General Test for SSD Portfolio Efficiency. OR Spectrum, 37(3), 703-734, https://doi.org/10.1007/s00291-014-0373-8

Kopa, M., Tichy, T. (2012). Concordance Measures and Second Order Stochastic Dominance Portfolio Efficiency Analysis. E+M Economics\&Management, 4, 110-120.

Kopa, M., Tichy, T. (2014). Comparison of Mean-Risk Efficient Portfolios in Asia-Pacific Capital Markets. Emerging Markets Finance and Trade, 50(1), 226-240, https://doi.org/10.2753/REE1540-496X500113

Kraus, A., Litzenberger, R. (1976). Skewness Preference and the Valuation of Risky Assets. Journal of Finance, 31(4), 1085-1099, https://doi.org/10.2307/2326275

Kuosmanen, T. (2004). Efficient Diversification According to Stochastic Dominance Criteria. Management Science, 50(10), 1390-1406, http://doi.org/10.1287/mnsc.1040.0284

Levy, Haim. (2006). Stocastic Dominance: Investment Decision Making under Uncertainty. Second Edition. New York: Springer Science. ISBN 978-1-4419-3983-8.

Linton, O., Post, T., Whang, Y. J. (2014). Testing for the Stochastic Dominance Efficiency of a Given Portfolio. Econometrics Journal, 17(2), 59-74, http://doi.org/10.1111/ectj.12016

Lizyayev, A. (2012). Stochastic Dominance Efficiency Analysis of Diversified Portfolios: Classification, Comparison and Refinements. Annals of Operations Research, 196(1), 391-410, http://doi.org/10.1007/s10479-012-1123-4

Markowitz, H. M. (1952). Portfolio Selection. Journal of Finance, 7(1), 77-91, http://doi.org/10.2307/2975974

Post, T. (2003). Empirical Tests for Stochastic Dominance Efficiency. Journal of Finance, 58(5), 1905-1932, http://doi.org/10.1111/1540-6261.00592

Post, T. (2008). On the Dual Test for SSD Efficiency, with an Application to Momentum Investment Strategies. European Journal of Operational Research, 185(3), 1564-1573, http://doi.org/10.1016/j.ejor.2006.08.010

Post, T., Fang, Y., Kopa, M. (2015). Linear Tests for DARA Stochastic Dominance. Management Science, 61(7), 1615-1629, http://doi.org/10.1287/mnsc.2014.1960

Post, T., Kopa, M. (2013). General Linear Formulations of Stochastic Dominance Criteria. European Journal of Operational Research, 230(2), 321-332, http://doi.org/10.1016/j.ejor.2013.04.015

Post, T., Van Vliet, P., Levy, H. (2008). Risk Aversion and Skewness Preference. Journal of Banking \& Finance, 32(7), 1178-1187, http://doi.org/10.1016/j.jbankfin.2006.02.008

Roman, D., Darby-Dowman, K., Mitra, G. (2006). Portfolio Construction Based on Stochastic Dominance and Target Return Distributions. Mathematical Programming, Ser. B, 108(2-3), 541-569, http://doi.org/10.1007/s10107-006-0722-8 
Sharpe, W. F. (1966). Mutual Fund Performance. Journal of Business, 39(1), 119-138, http://doi.org/10.1086/294846

Sharpe, W. F. (1994). The Sharpe Ratio. The Journal of Portfolio Management, 21(1), 49-58, https://doi.org/10.3905/jpm.1994.409501

Tas, O., Barjiough, F. M., Ugurlu, U. (2015). A Test of Second-Order Stochastic Dominance with Different Weighting Methods: Evidence from BIST-30 and DJIA. Journal of Business Economics and Finance, 4(4), 723-731, http://doi.org/10.17261/Pressacademia.2015414538

Treynor, J. L. (1966). How to Rate Management Investment Funds. Harvard Business Review, 43(1), January-February, 63-75. 